\title{
ANOMALIAS DE DRENAGEM NO RIBEIRÃO DOS RODRIGUES: CONTRIBUIÇÕES SOBRE A GEOMORFOLOGIA DA REGIÃO DE SOROCABA-SP
}

\begin{abstract}
André de Oliveira Souza ${ }^{1}$ Emerson Martins Arruda ${ }^{2}$

Resumo: Este artigo propõe-se a discutir a interação de processos denudacionais com aqueles de origem tectônica no controle da dinâmica geomorfológica da bacia do Ribeirão dos Rodrigues, localizada nos municípios de Salto de Pirapora, Pilar do Sul e Sarapuí na região de Sorocaba-SP. O estudo foi realizado a partir da aplicação de técnicas morfométricas (RDE, Perfil Longitudinal, cálculos da área da bacia, do comprimento do curso principal e hierarquia fluvial), elaboração do mapa de lineamentos e trabalhos de campo. A partir dos resultados obtidos verificou-se uma integração de sistemas litológicos, estruturais e erosivos na dinâmica epirogênica e neotectônica da área.
\end{abstract}

Palavras-chave: Anomalias de Drenagem; Neotectônica; Denudação.

\section{DRAINAGE ANOMALIES IN RIBEIRÃO DOS RODRIGUES: CONTRIBUTIONS TO GEOMORPHOLOGY OF THE SOROCABA REGION, SP}

\begin{abstract}
This paper aims to discuss the interaction of denudational processes with those of tectonic origin in the control of geomorphological dynamics of Ribeirão dos Rodrigues basin located in Salto de Pirapora and Pilar do Sul counties in the Sorocaba region. The study was conducted based on the application of morphometric techniques (RDE, Longitudinal Profile, basin area calculations, of main river length and fluvial hierarchy), preparation of the lineament map and fieldworks. From the results obtained it was possible to verify that there was an integration of systems lithological, structural and erosive systems in the epirogenic and neotectonics dynamics of the area.
\end{abstract}

Key words: Drainage Anomalies; Neotectonics; Denudation.

\section{INTRODUÇÃO}

Durante o desenvolvimento e evolução do relevo tem-se a interferência de diversos fatores que, interagindo de modo sistêmico, são responsáveis pelas atuais formas encontradas. Tal processo é controlado por diferentes aspectos relacionados ao clima, estrutura e litologia de

1. Pós-graduando no Departamento de Geografia da UNICAMP (andreosouza@ige.unicamp.br).

2. Professor Doutor do Departamento de Geografia e Humanidades da UFSCar, campus Sorocaba (emersongeo@ufscar.br). 
uma área. Do mesmo modo, as formas impressas na atual paisagem são consequência de uma sucessão de processos vinculados a temporalidades e escalas espaciais distintas.

Boer (1992) afirma que a forma e o funcionamento de qualquer sistema geomorfológico é o produto final da interação de processos em todos os níveis de escala. Nesta perspectiva, Phillips (2005) aponta que em muitos casos os comportamentos estável e instável podem ser observados no mesmo sistema, no entanto em escalas diferentes.

A partir disso, pode-se afirmar que o entendimento do relevo perfaz a análise de diferentes aspectos naturais e abordagens teóricas. Bishop (2007) aponta que a partir da década de 1950 diversas teorias buscaram compreender os processos relacionados ao desenvolvimento do relevo, sobretudo, buscando a superação do pensamento davisiano. 0 autor afirma que a abordagem sistêmica e a revolução quantitativa, assim como as proposições de John Hack, tiveram um papel importante na revitalização dos estudos sobre a evolução da paisagem.

Neste trabalho buscou-se estudar a evolução do relevo a partir das anomalias de drenagem e processos atuantes em diferentes níveis escalares (espaciais e temporais), bem como a importância dos processos erosivos denudacionais em relação aos condicionantes litológicos e atividades tectônicas recentes. Neste âmbito, é possível afirmar que a organização da rede de drenagem da bacia do Ribeirão dos Rodrigues, localizado na região de Sorocaba-SP, é reflexo de controles que acontecem não apenas na escala local, mas também como consequência dos processos regionais.

Os estudos de cunho geomorfológico na região ainda são incipientes, embora hajam diversos elementos naturais (a exemplo do Morro de Ipanema e da Serra de São Francisco) e socioambientais (a exemplo da Represa de Itupararanga), que compõem um mosaico de fatos geomorfológicos e, portanto, se constituem como objetos de estudos da ciência geomorfológica.

Alguns trabalhos têm levantado importantes questões acerca dos processos litoestruturais da região, inclusive referentes à dinâmica neotectônica. Pesquisas relacionadas ao enfoque ambiental também foram desenvolvidas a partir dos trabalhos de Souza e Arruda (2012) e Morais e Arruda (2012). 
Em relação à morfoestrutura, Santos Neto e Arruda (2012) demonstraram a existência de formas e feições que indicam pulsos tectônicos ocorridos durante o Quaternário, responsáveis pela deformação de litologias e pela compartimentação da bacia hidrográfica do Ribeirão Jurupará, o qual disseca parte da Serra de São Francisco. O trabalho citado discorre que a referida serra é, em parte, responsável pelo sistema de represamento de Itupararanga e, portanto, entender a dinâmica da mesma representa grande interesse não apenas para a comunidade científica, mas para a sociedade e gestores.

Villela et al. (2013), analisando a relação relevo-rocha-solo no município de Sorocaba, identificou controles diferentes para o desenvolvimento das formas encontradas na paisagem, principalmente em relação aos tipos de rochas, solos e características dos interflúvios, uma vez que a área estudada pelos autores abarca o contato entre dois compartimentos geomorfológicos, Planalto Atlântico e Depressão Periférica Paulista.

Em relação às anomalias de drenagem, diversos trabalhos têm apontado para o controle litoestrutural como causa dessas feições na rede de drenagem. Bishop (1995) afirma que podem ser identificadas três formas de rearranjo da rede de drenagem, chamadas por ele de captura, desvio e decapitação. Para este autor todas essas formas são úteis para distinguir entre um rearranjo da bacia hidrográfica e rearranjo de determinada linha de drenagem. A diferença entre ambos envolve invasão progressiva de um sistema em outro adjacente, resultando na transferência de uma área drenada para outro sistema fluvial. Nesse processo há transferência tanto de áreas inteiras como de canais, com a preservação de parte do canal original da antiga área drenada.

Howard (1967) aponta que as anomalias de drenagem ao longo de uma bacia hidrográfica podem ser representadas por trechos em que há retilinidade de canais fluviais, ocorrência localizada e abrupta de curvas meândricas, trechos de meandros comprimidos, estreitamento e alargamento de fundo de vales com preenchimentos aluviais, represamentos com desenvolvimento de trechos embrejados, e curvas e voltas abruptas na drenagem.

No Brasil, estudos que relacionam as anomalias de drenagem com a evolução do relevo são desenvolvidos desde a década de 1950, a exemplo de Ab'Saber (1956) que teceu considerações sobre o "cotovelo de Guararema"; posteriormente Riccomini et al. (2010) 
apresentaram novas contribuições sobre o assunto. Christofoletti (1977) relacionou as capturas de drenagem com a existência de níveis de base em diferentes escalas, afirmando que as mesmas não acontecem em decorrência da retração de cabeceiras de drenagens devido ao equilíbrio dinâmico. Salienta-se que, Bishop (1995) apresentou modelo que contrapõe a perspectiva de Christofoletti (1977). Outros trabalhos como de Oliveira e Queiroz Neto (2007), indicaram processos de pirataria fluvial influenciando na morfogênese da Serra do Mar.

A partir da década de 90 importantes trabalhos de geomorfologia analisam a organização dos sistemas de drenagem como indicadores de manifestações neotectônicas. No sudeste brasileiro trabalhos como os desenvolvidos por Salvador e Riccomini (1995), Gontijo (1999), Hiruma (1999), Etchebehere (2000), Mendes et al. (2007) e Arruda (2008) contribuíram para a compreensão das anomalias de drenagem como respostas morfológicas aos rearranjos e pulsos tectônicos recentes.

De modo geral, o objetivo desse artigo é expor os resultados das pesquisas geomorfológicas realizadas na bacia do Ribeirão dos Rodrigues, localizada nos municípios de Salto de Pirapora, Pilar do Sul e Sarapuí, região de Sorocaba-SP. Espera-se, deste modo, contribuir para a compreensão da dinâmica geomorfológica e neotectônica não apenas da bacia em si, mas de áreas adjacentes.

\section{ÁREA DE ESTUDO}

A bacia hidrográfica do Ribeirão dos Rodrigues está localizada nos municípios de Salto de Pirapora, Pilar do Sul e Sarapuí, porção sul-sudeste do Estado de São Paulo. Insere-se entre

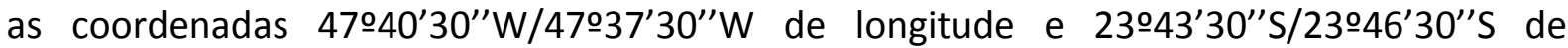
latitude (Figura 1), distando aproximadamente $30 \mathrm{~km}$ de distância do município de Sorocaba. O acesso bacia é realizado através da rodovia João Leme dos Santos (SP-264) e estradas vicinais.

O curso principal possui aproximadamente $27 \mathrm{~km} \mathrm{e}$, juntamente com seus afluentes, drena uma área de $33 \mathrm{~km}^{2}$. As nascentes do Ribeirão dos Rodrigues estão localizadas na Serra dos Lopes a 800-850 metros de altitude e sua foz, no rio Sarapuí, a 580 metros. O sistema fluvial é de 5 a ordem hierárquica (Strahler, 1975), o qual possui 105 cursos de 1a ordem, 39 cursos 
de $2^{\underline{a}}$ ordem, 5 curso de $3^{\underline{a}}$ ordem, 2 cursos de $4 \underline{a}$ ordem e 1 curso de $5^{a}$ ordem correspondente ao rio principal.

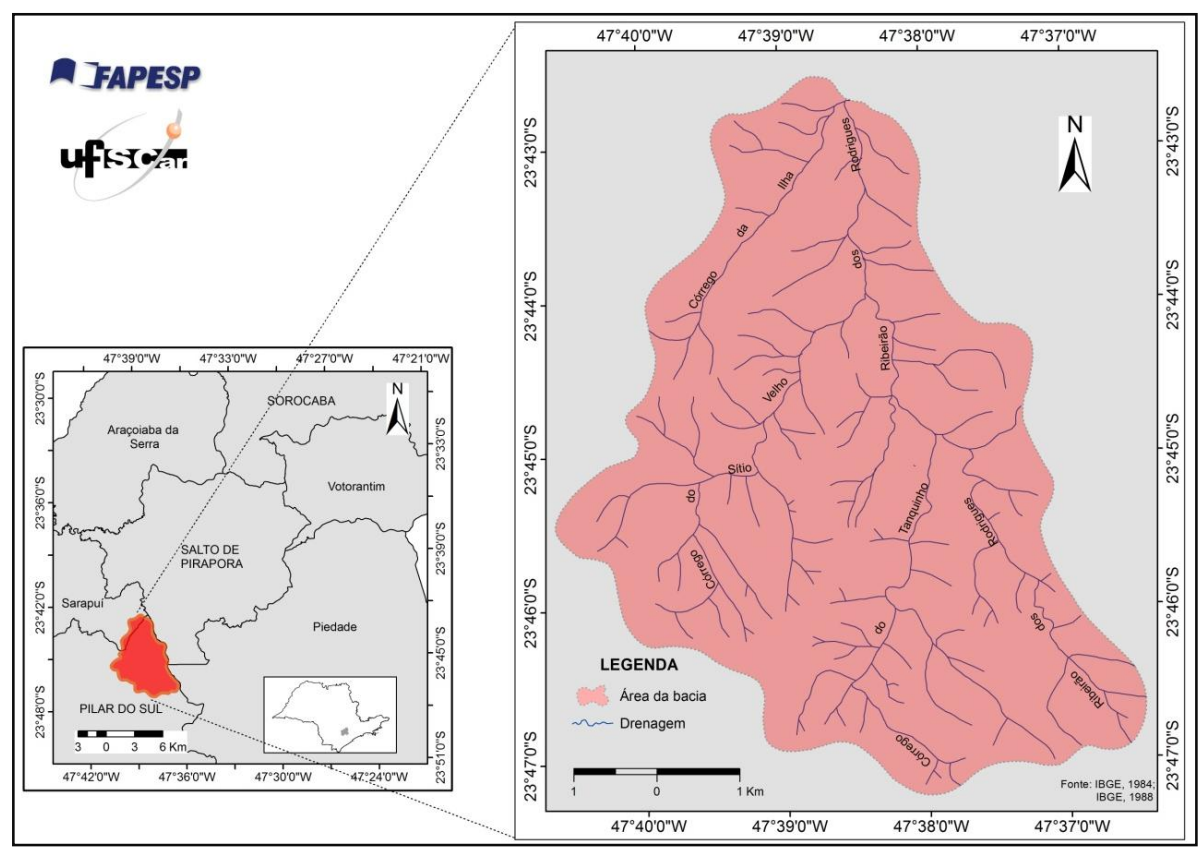

Figura 1: Mapa da Bacia do Ribeirão dos Rodrigues.

\section{ASPECTOS LITOESTRUTURAIS}

A complexidade litológica da área estudada está associada à sucessão de eventos tectônicos e climáticos, responsáveis pela deposição de rochas sedimentares permocarboníferas, sobre litologias cristalinas relacionadas ao Cinturão Orogênico do leste paulista pertencentes à Era Proterozóica.

No âmbito das litologias cristalinas, são encontradas na área rochas ígneas e metamórficas. O primeiro litotipo possui aproximadamente 1,4 Ga sendo correlacionável com o final do Ciclo Transamazônico, período em que havia a fragmentação do mega continente Colúmbia (Hasui, 2010).

As litologias magmáticas encontradas na área podem ser correlacionadas ao Ciclo Brasiliano (601 Ma), referentes à fragmentação do paleocontinente Rodínia (Hasui, 2010), e estão vinculadas à última reativação significativas da Zona de Cisalhamento de Taxaquara durante o Neoproterozóico (Hasui et al.,1977).

As litologias permo-carboníferas estão representadas na área pelo Grupo Itararé, composto por arenitos, argilitos, folhelhos, siltitos, ritmitos e diamictitos, onde a sua deposição está 
vinculada aos períodos de glaciações e deglaciações ocorridos durante o Permiano e Carbonífero (VESELY e ASSINE, 2006; SÃO PAULO, 2009). As litologias mais comuns na área são os arenitos com estratificação cruzada e acanalada, cuja granulação varia de muito fina a grossa, frequentemente feldspática, com predomínio de matriz síltica-argilosa (MASSOLI, 1991).

Estruturalmente a área de estudos é intersectada por duas importantes Zonas de Cisalhamento. À jusante encontra-se a Zona de Cisalhamento de Moreira de orientação NESW e, a montante, a Zona de Cisalhamento de Taxaquara de orientação SSW-NE; ambas possuem características transcorrentes.

Esses sistemas de falhas também sofreram interferência dos processos responsáveis pela gênese do Rift Continental do Sudeste Brasileiro (Riccomini, 1989), onde se sucederam esforços extensionais, transcorrentes e compressionais durante o Cenozoico, que acabaram por originar o Vale do Paraíba.

\section{ASPECTOS GEOMORFOLÓGICOS}

Os municípios de Salto de Pirapora, Pilar do Sul e Sarapuí estão inseridos na transição entre dois importantes compartimentos geomorfológicos do estado de São Paulo, denominado por Almeida (1964) como Planalto Atlântico e Depressão Periférica. No entanto, observa-se que em decorrência dos processos erosivos a Depressão Periférica nesta área adentra ao setor cristalino, originando uma superfície correspondente à Superfície Fóssil PréCarbonífera (Ab'Saber, 1969) localizada nas cotas de 700 a $720 \mathrm{~m}$.

As cabeceiras da alta bacia do Ribeirão dos Rodrigues estão posicionadas na Serra dos Lopes no município de Pilar do Sul, com altitudes que chegam à cota de 900 metros (Figura 2). Essa importante forma está inserida no Planalto Cristalino, que nesta área tem a sua transição com a Depressão Periférica marcada pela Zona de Cisalhamento de Taxaquara. As áreas correspondentes a Serra dos Lopes também apresentam as maiores declividades da bacia do Ribeirão dos Rodrigues, as quais estão relacionadas ao controle litológico e estrutural.

$\mathrm{Na}$ Depressão Periférica Paulista os topos dos interflúvios da bacia estudada se correlacionam com as superfícies Neogênicas (Ab'Saber, 1949, 1969), Superfície Pd2 (Bigarella et. al, 1965) e Superfície Sul Americana I (Valadão, 1998). 
Do mesmo modo, o setor cristalino da área está vinculada à Superfície Itaguá (Ponçano e Almeida, 1993) e Pd3 (Bigarella et. al, 1965) e Sul Americana (Valadão, 1998).

Na Serra dos Lopes, ocorrem vales em "V", vertentes retilíneas e convexo-côncavas, além de rupturas topográficas marcadas por altos valores de declividade.

Nas áreas localizadas na média e baixa bacia predominam vales de fundo plano com planícies e terraços bem delimitados, correspondendo aos setores de maior acúmulo de sedimentos. As vertentes são côncavas, convexo-côncavas e convexas. Embora apresente baixas declividades, em alguns setores maiores valores se destacam (Vale do Ribeirão dos Rodrigues, contato com a escarpa da Serra dos Lopes, Córrego da Ilha), uma vez que identificados expressivos lineamentos, refletindo-se em rupturas topográficas significativas.

\section{ASPECTOS PEDOLÓGICOS}

A caracterização pedológica da área teve como referência uma abordagem regional, tendo em vista a escassez de estudos pedológicos na escala de detalhe (1:10.000). Deste modo, foram identificados Latossolos, principalmente no setor correspondente à Depressão Periférica Paulista; Cambissolos e Neossolos Litólicos (Vitte, 2005) nas proximidades das cabeceiras de drenagem na Serra dos Lopes. 


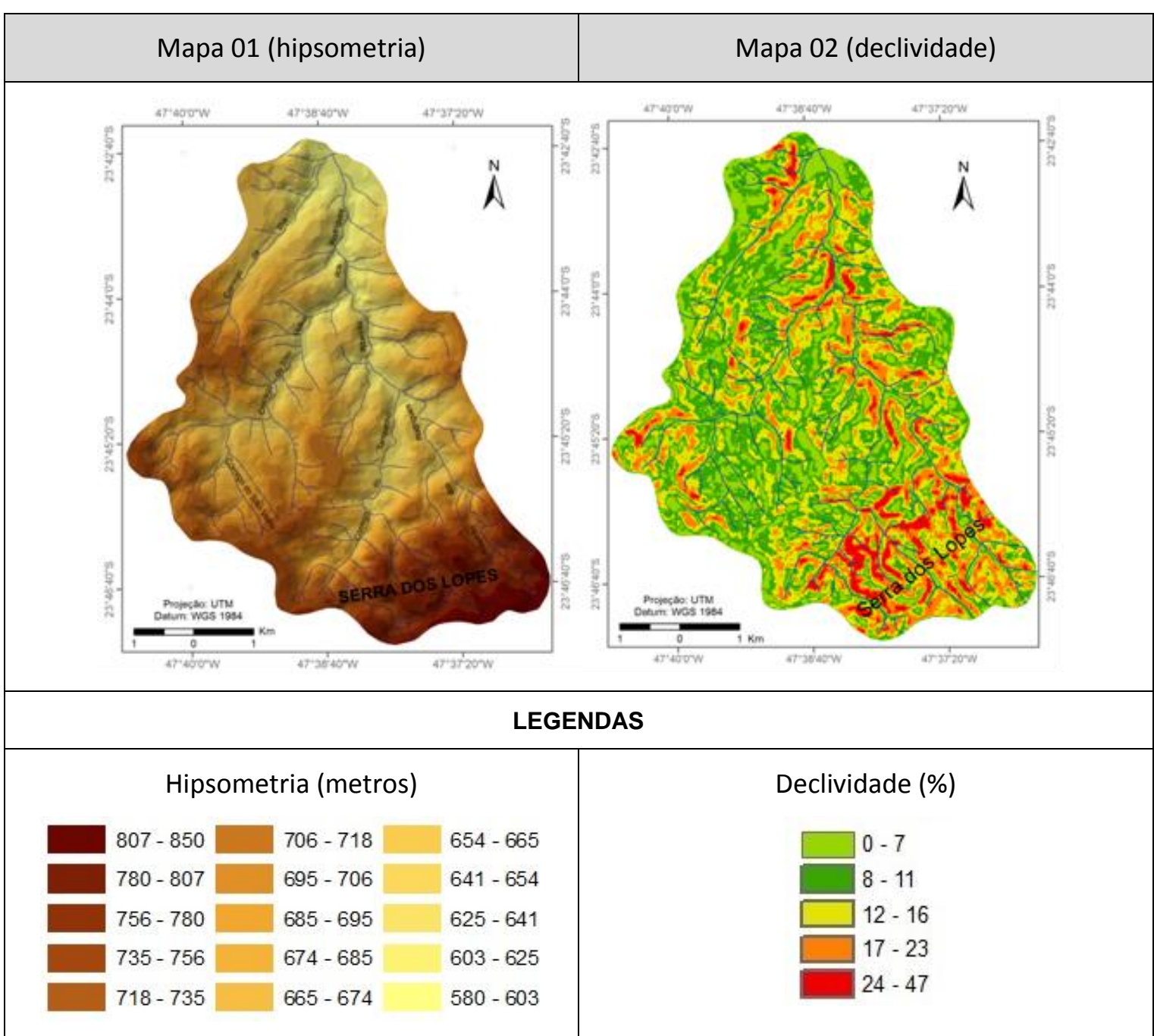

Figura 2: Mapas hipsométrico (1) e de declividade (2) da área de estudos. Organização: Souza e Arruda, 2014.

\section{ASPECTOS CLIMÁTICOS}

A área em questão é caracterizada por clima tropical alternadamente seco e úmido (Monteiro, 1973). Entretanto, segundo o autor, a porção do relevo inserida no Planalto Atlântico possui climas úmidos da face oriental e subtropical dos continentes, onde é dominado pelas massas tropicais polares.

Ainda de acordo com o autor, a umidade relativa da área de estudo varia entre $75 \%$ e $80 \%$ com gradiente de pluviosidade variando entre 1100 e $1300 \mathrm{~mm}$ ao ano, segundo dados do Centro de Pesquisas Meteorológicas e Climáticas Aplicadas a Agricultura - CEPAGRI. 


\section{MATERIAIS E MÉTODO}

A metodologia utilizada compreendeu a aplicação de índices morfométricos relacionados ao relevo e à drenagem, bem como a elaboração de mapas temáticos. Foram realizadas medições referentes à área da bacia, comprimento do curso principal e hierarquia fluvial, além do cálculo de Fator de Simetria Topográfica Transversa (Cox, 1994) e da Relação Declividade-Extensão (HACK, 1973; ETCHEBEHERE, 2000; ETCHEBEHERE et al., 2004) juntamente com a elaboração de perfis longitudinais (Bishop et al., 1985; Guedes et al., 2006). No âmbito de mapeamento, foi elaborado o mapa regional de lineamentos e gráficos de rosetas com a direção dos mesmos. Além disso, foram realizados trabalhos de campo na área de estudos e entorno.

Salienta-se que parte das análises morfométricas e elaboração cartográfica foi realizada a partir do banco de dados SRTM (Shuttle Radar Topography Mission), manipulados através do software ArcGis 10.

\section{RESULTADOS E DISCUSSÕES}

Drenando uma área aproximada de $33 \mathrm{~km}^{2}$, a bacia hidrográfica do Ribeirão dos Rodrigues é classificada como de 5a ordem de acordo com a classificação de Strahler (1957); o curso principal possui 27 quilômetros de comprimento. A área de estudos apresenta diversas evidências da interação entre processos denudacionais e neotectônicos vinculados a dinâmica dos principais compartimentos geomorfológicos do Estado de São Paulo. Tais evidências serão apresentadas adiante.

Na Figura 3 é possível visualizar ao fundo a escarpa da Serra dos Lopes e a transição de terrenos cristalinos para sedimentares, marcado pelo vale correspondente a Zona de Cisalhamento de Taxaquara. É também possível notar evidências de processos denudacionais intensos (formas arredondadas), sendo bastante comum a presença de matacões no topo da serra, que correspondem à exumação de litologias do embasamento.

A pequena espessura de solos encontrados na Serra dos Lopes (Figura 4) corrobora com a atuação intensa desses processos erosivos que também ocultam feições neotectônicas evidentes apenas na elaboração do modelo tridimensional do relevo da bacia (Figura 1). 


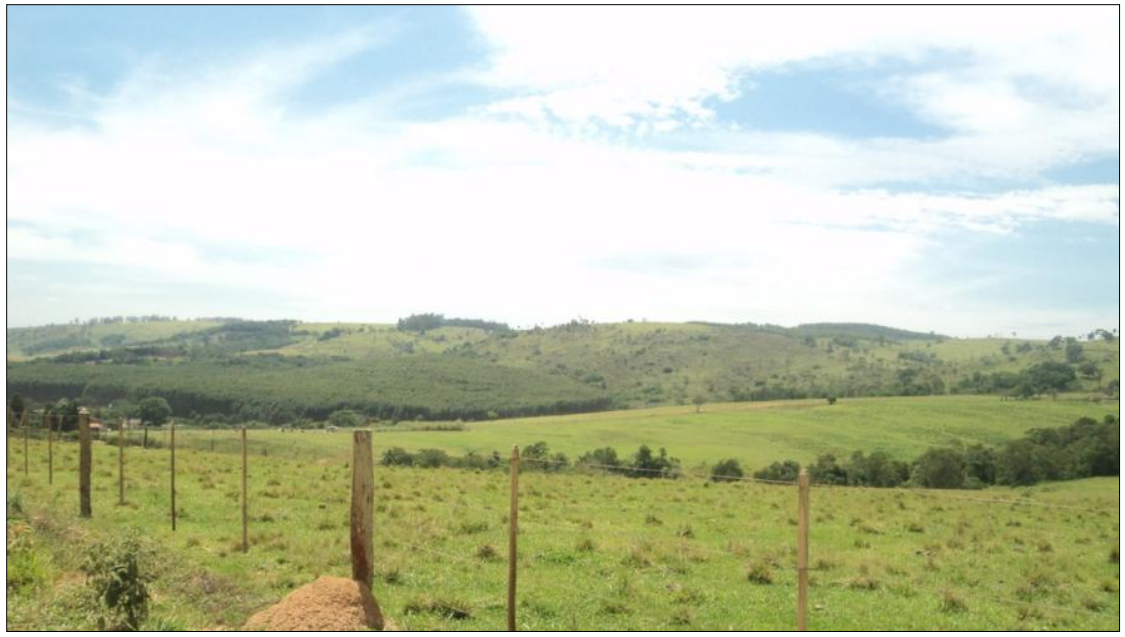

Figura 3: Escarpa da Serra dos Lopes. Fonte: Souza (2013).

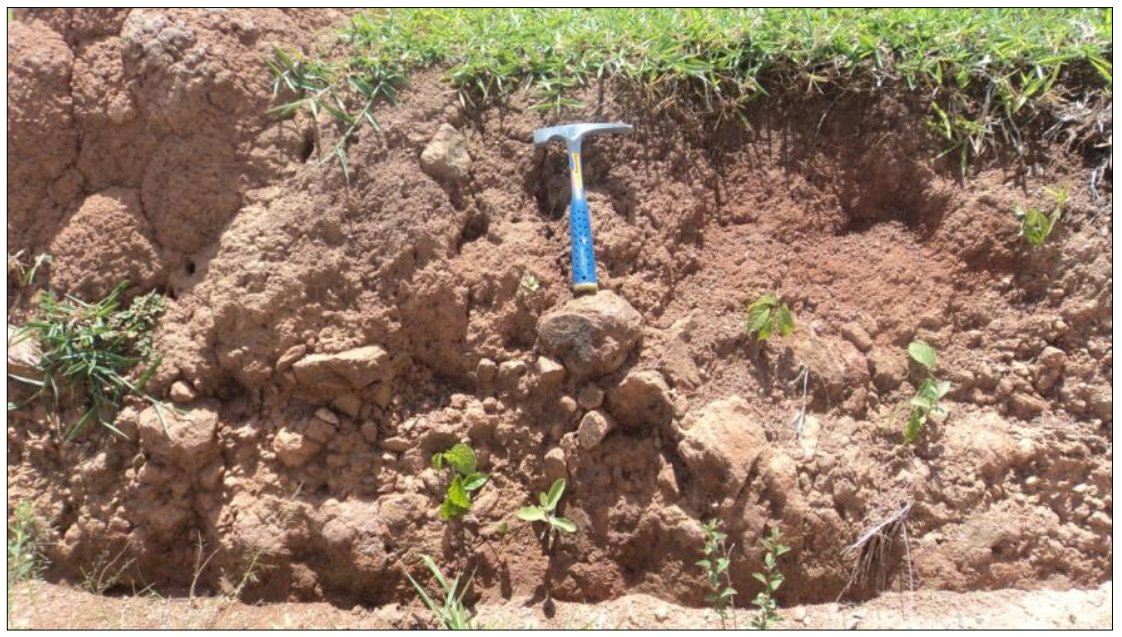

Figura 4: Presença de solo incipiente no topo da Serra dos Lopes. É possível observar o horizonte C e o desenvolvimento de um incipiente horizonte $\mathrm{A}$.

Fonte: Souza (2013).

A complexidade de processos que dinamizam as regiões tropicais e intertropicais úmidas, do ponto de vista geomorfológico, também está associada aos condicionantes climáticos que devido à grande intensidade do intemperismo mascara as feições que poderiam subsidiar os estudos sobre a gênese e desenvolvimento das formas de relevo; e, portanto, são necessárias técncias que contribuam para a análise geomorfológica, neste caso, o modelo tridimensional do relevo (Figura 5) que possibilitou a identificação de facetas triangulares na Serra dos Lopes. 


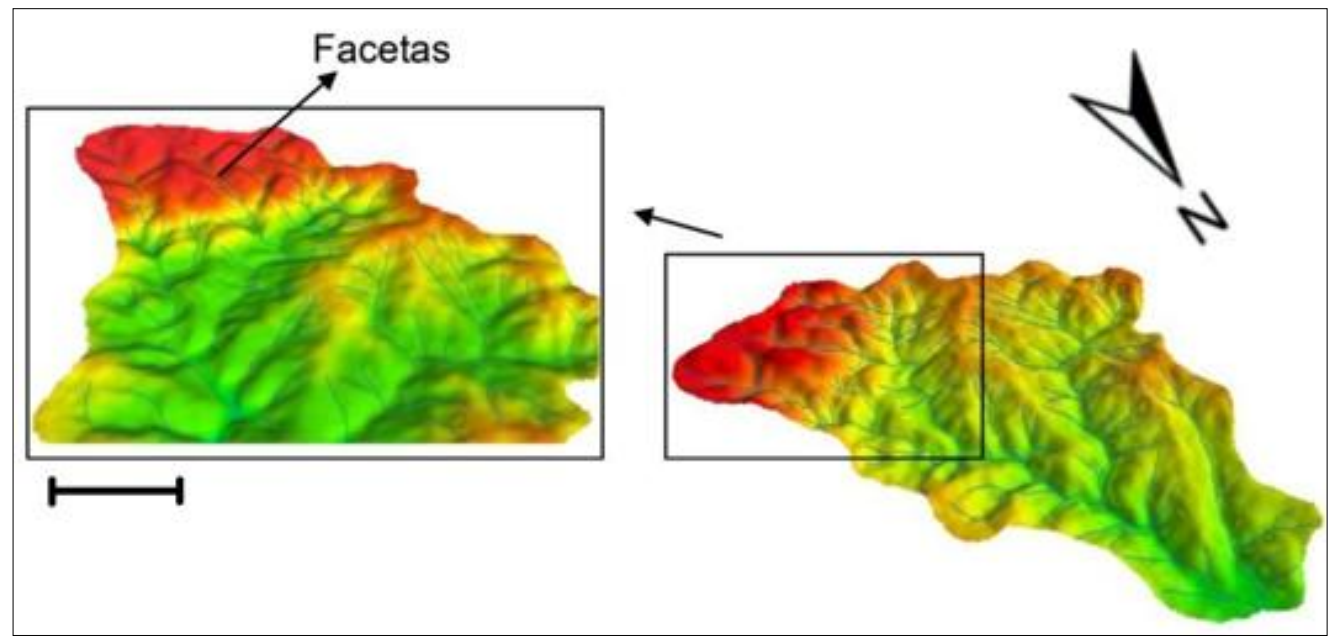

Figura 5: Representação tridimensional do relevo da bacia do Ribeirão dos Rodrigues. Fonte: Souza (2013).

O mapeamento dos 239 lineamentos (Figura 6) identificados na área e adjacências tornou evidente que as principais falhas e as formas a elas associadas (lineamentos de interflúvios, rios retilíneos, entre outros) seguem na direção NNE e NE (Figura 7), os quais correspondem também às principais orientações dos "trends" do Cinturão Orogênico. Deste modo, permite formular a hipótese de reativações durante o Neógeno e Quaternário, principalmente no que tange a Zona de Cisalhamento de Taxaquara.

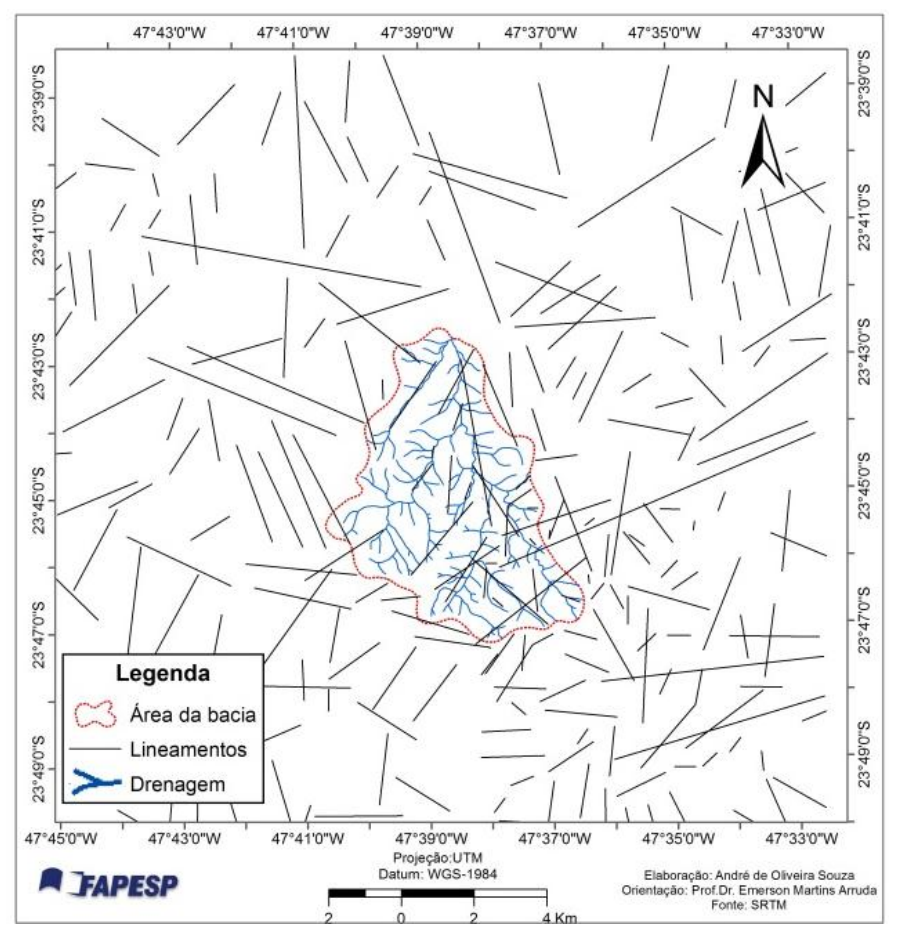

Figura 6: Lineamentos na bacia do Ribeirão dos Rodrigues e adjacências. 


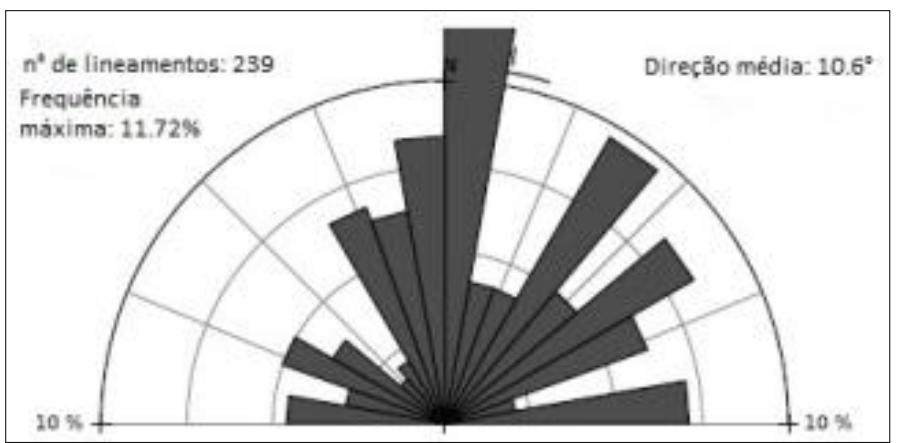

Figura 7: Roseta com as principais direções de lineamentos. Fonte: Souza (2013).

Desse modo, o lineamento no qual o Ribeirão dos Rodrigues está encaixado corresponde a uma falha secundária que induziu a uma migração deste rio para leste, da mesma maneira que tal controle estrutural também é responsável pela assimetria na bacia identificada através da aplicação do índice de Cox (1994) para o curso principal, isto é, o valor médio foi de $T=0,51$ e em alguns trechos na alta-média bacia o valor se aproximou de $T=1$. Salienta-se que quanto maior for esse índice, mais assimétrica é a bacia.

Portanto, é possível que os movimentos transcorrentes decorrentes de reativações tenham proporcionado a atual organização desse trecho da bacia, controlando inclusive a dissecação do vale, uma vez que o mesmo se encontra bastante encaixado.

Regionalmente o controle erosivo tem como principal nível de base o rio Sarapuí, no qual a drenagem estudada deságua. No entanto, o conjunto de falhas evidenciadas no mapa de lineamentos ajuda a compor uma série de níveis de base intermediários que também possuem um papel fundamental na evolução das encostas e, consequentemente na modelagem do relevo, formação de depósitos correlativos e elaboração de superfícies erosivas.

As rupturas no relevo ou knick-points ficaram evidentes nos valores do índice RDE (Tabelas 1, 2 e 3) no curso principal do Ribeirão dos Rodrigues e em dois de seus afluentes. Foram considerados anômalos valores a partir de 2 (dois), sendo estes considerados anomalias de primeira ordem.

Salienta-se que os resultados do índice RDE foram obtidos a partir do cálculo das variáveis de acordo com as seguintes fórmulas:

1) $\operatorname{RDE}_{\text {trecho }}=(\Delta \mathrm{h} / \Delta \mathrm{l}) \times \mathrm{L}$ 
2) $R_{D E} E_{\text {total }}=\Delta h \div \log L$

\begin{tabular}{|c|c|c|c|c|r|}
\hline Curva (metros) & $\Delta \mathbf{H}$ (metros) & $\Delta \mathbf{l}$ (metros) & $\mathbf{L}$ (metros) & $\begin{array}{c}\text { RDEtrecho } \\
\text { (metros) }\end{array}$ & $\begin{array}{r}\text { RDEtrecho/ } \\
\text { RDEtotal } \\
\text { (metros) }\end{array}$ \\
\hline 820 & 20 & 260 & 117 & 8,9 & 0,1 \\
\hline 800 & 20 & 268 & 363 & 27 & 0,4 \\
\hline 780 & 20 & 398 & 802 & 40,3 & 0,67 \\
\hline 760 & 20 & 558 & 1359 & 48,7 & 2,08 \\
\hline 740 & 20 & 273 & 1714 & 125 & 2,3 \\
\hline 720 & 20 & 291 & 2046 & 140,6 & 5,7 \\
\hline 700 & 20 & 125 & 2155 & 344,8 & 1,53 \\
\hline 680 & 20 & 612 & 2821 & 92,18 & 1,6 \\
\hline 660 & 20 & 744 & 3573 & 96,04 & 2,65 \\
\hline 640 & 20 & 638 & 5083 & 159,34 & 1,25 \\
\hline 620 & 20 & 1905 & 7145 & 75,01 & 1,76 \\
\hline 600 & 20 & 1784 & 9430 & 105,7 & 58,55 \\
\hline 580 & 20 & 1171 & 10042 & 171,5 & \\
\hline
\end{tabular}

Tabela 1: Valores RDE do Ribeirão dos Rodrigues.

Fonte: Souza e Arruda (2014).

Organização: Souza e Arruda (2013).

\begin{tabular}{|c|c|c|c|c|c|}
\hline Curva (metros) & $\Delta \mathbf{H}$ (metros) & $\Delta \mathbf{l}$ (metros) & $\mathbf{L}$ (metros) & $\begin{array}{c}\text { RDEtrecho } \\
\text { (metros) }\end{array}$ & $\begin{array}{c}\text { RDEtrecho/ } \\
\text { RDEtotal } \\
\text { (metros) }\end{array}$ \\
\hline 760 & 20 & 731,83 & 769,78 & 29,35 & 0,78 \\
\hline 740 & 20 & 311,12 & 1094,11 & 89,89 & 2,4 \\
\hline 720 & 20 & 244,46 & 1354,46 & 135,7 & 3,62 \\
\hline 700 & 20 & 234,35 & 1613,5 & 163,66 & 4,37 \\
\hline 680 & 20 & 1024,11 & 2597,43 & 56,66 & 1,51 \\
\hline 660 & 20 & 200,24 & 2917,04 & 321,74 & 9,67 \\
\hline 640 & 20 & 1667,59 & 4788,47 & 61,07 & 1,63 \\
\hline
\end{tabular}

Tabela 2: Valores de RDE do Córrego do Tanquinho.

Fonte: Souza e Arruda (2014).

Organização: Souza e Arruda, 2013.

Como podem ser observados, os maiores valores de RDE encontrados são referentes à escarpa da Serra dos Lopes (720 e 740 metros). Essa ruptura topográfica está marcada principalmente nos valores para o Ribeirão dos Rodrigues e Córrego do Tanquinho. As principais anomalias encontradas nesse setor correspondem a desvios na drenagem que se caracterizam como inflexões, podendo estar vinculados aos movimentos transcorrentes da Zona de Cisalhamento de Taxaquara.

O perfil longitudinal do Ribeirão dos Rodrigues (Figura 8) mostrou setores com anomalias positivas (côncavo acima da linha de tendência) e negativas (côncavo abaixo da linha de tendência), sugerindo atividades e movimentos correlatos. Neste sentido, os referidos trechos estão associados às facetas triangulares e rupturas identificadas no relevo, inclusive 
setores onde a drenagem evidencia uma recente reorganização a partir de cabeceiras bem dissecadas e ravinamentos.

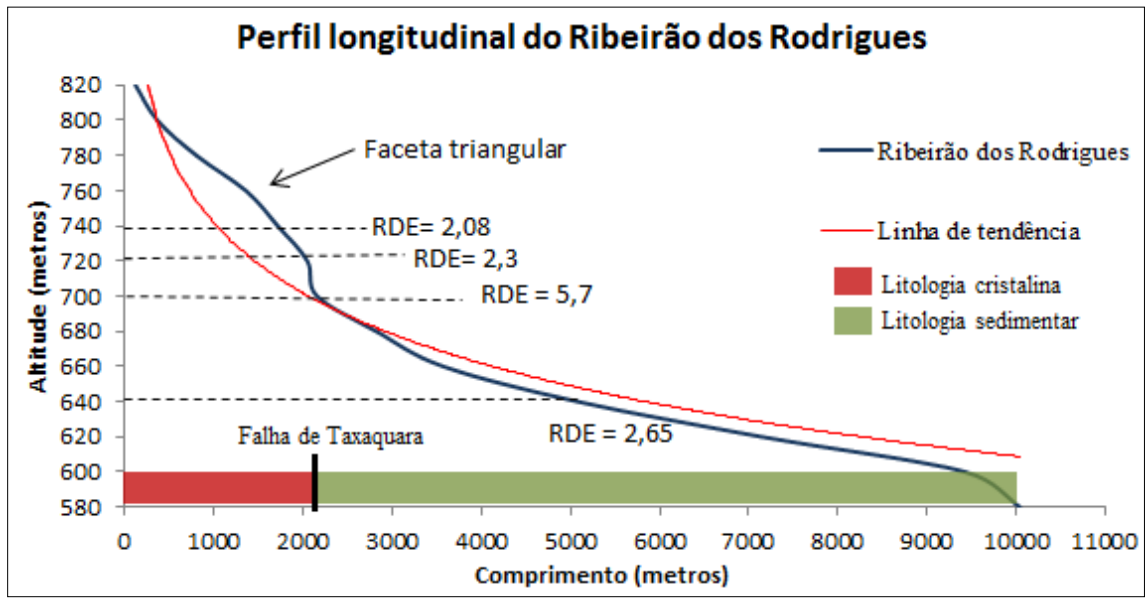

Figura 8: Perfil Longitudinal do Ribeirão dos Rodrigues. É possível notar setores discordantes com a linha de tendência, sobretudo no alto curso.

Fonte: Souza e Arruda (2014).

Segundo Guedes et al. (2006) estas anomalias podem mostrar áreas onde estão ocorrendo soerguimentos. No caso, as facetas triangulares identificadas corroboram com a hipótese de uma epirogênese positiva.

O perfil longitudinal do Córrego do Tanquinho (Figura 9) apontou alguns setores com importantes knicks points, assim como expressivas anomalias negativas, podendo essas estar associadas à subsidência deste trecho da bacia estudada.

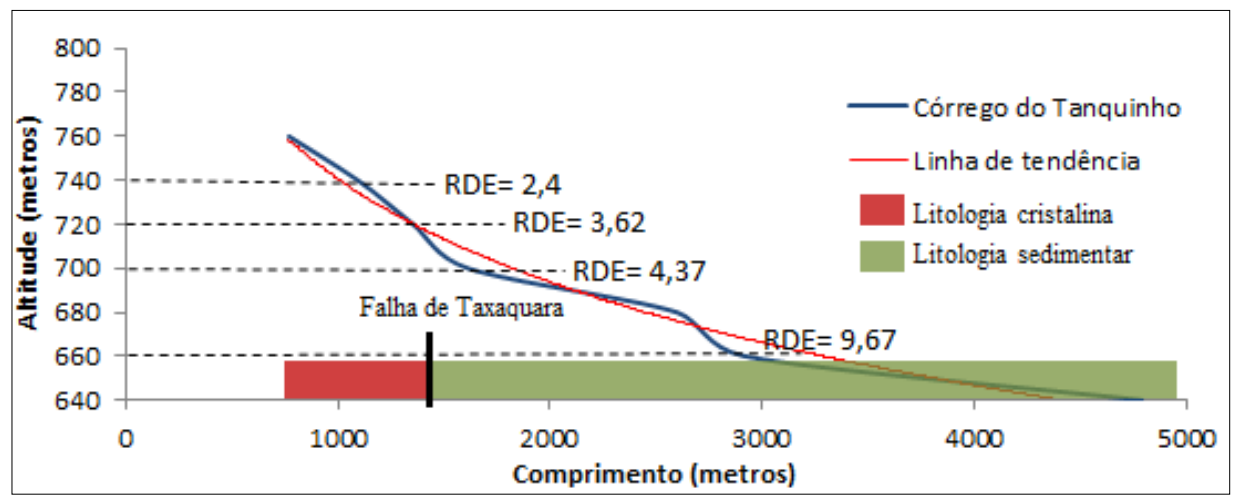

Figura 9: Perfil Longitudinal do Córrego do Tanquinho. Possível observar uma sequência de knick-points correspondentes às cotas de 700 e 660 metros de altitude.

Fonte: Souza e Arruda (2014).

As anomalias mais significativas do perfil longitudinal, em relação à linha de tendência, ocorrem entre as cotas altimétricas de 720 e 700 metros, representados por inflexões de trechos do córrego, indicando possíveis capturas fluviais. Bishop (1995) aponta que a declividade é um dos três fatores que possibilitam a ocorrência de capturas fluviais; sendo 
assim, verificou-se que a área possui setores com altas declividades e uma possível subsidência do relevo nos setores que compreendem a média e baixa bacia, fatores esses envolvidos nos processos de capturas. A área compreendida entre cotas altimétricas de 680 a 660 metros apresentou valores altos de RDE total (9,67 no caso da cota de 660 metros), correspondentes às formas côncavas do perfil longitudinal acima e abaixo da linha de tendência. Essa forma encontrada do perfil é resultado dos controles litológicos e estruturais da área.

A Figura 10 e a Figura 11 mostram interflúvios que foram desarticulados em decorrência de possíveis processos de shutter ridges que causa desvio ao Córrego do Tanquinho para contorná-lo. Salienta-se que neste setor o referido rio apresenta altos valores de $\operatorname{RDE}(9,67)$, ruptura no Perfil Longitudinal, declividade acentuada e, consequentemente, configura-se como uma anomalia de drenagem.

Possivelmente em decorrência de uma alteração subatual do nível de base, vinculada a reativação de antigas falhas, os processos erosivos se intensificaram, proporcionando assim, o desencadeamento de feições lineares identificadas a partir de cicatrizes relacionadas a movimentos de massas recentes e que estão impressos na paisagem.

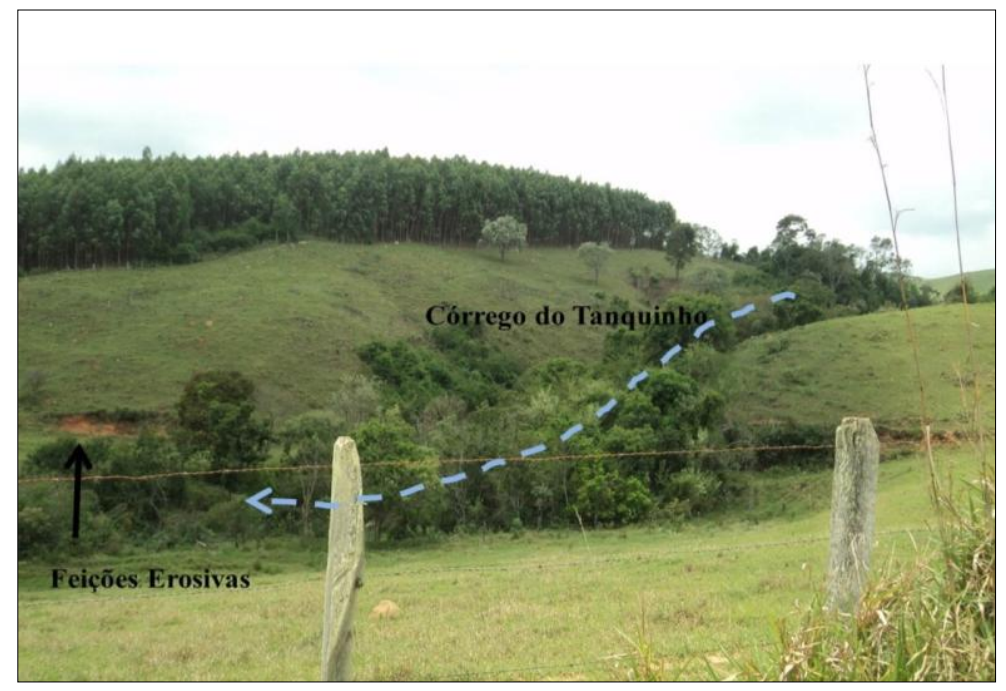

Figura 10: Interflúvio à esquerda na foto, o qual foi responsável pelo desvio do rio. A linha tracejada azul corresponde ao traçado do Córrego do Tanquinho.

O Córrego do Sítio Velho constitui um dos afluentes da margem esquerda do Ribeirão dos

Rodrigues e, assim como os outros rios analisados, também possui feições que caracterizam anomalias de drenagem, como trechos retilíneos e inflexões abruptas. No entanto, ao 
contrário do Ribeirão dos Rodrigues e do Córrego do Tanquinho esse rio drena um setor do relevo que possui litologias pertencentes apenas ao Subgrupo Itararé.

Na Relação Declividade-Extensão os valores apresentaram algumas anomalias vinculadas à linearidade do trecho correspondente às cotas altimétricas de 700 e 680 metros, do mesmo modo que tais índices se correlacionam a inflexão que o córrego realiza, alterando seu traçado de SE para N.

Em relação ao Córrego do Sítio Velho, este não apresenta grandes declividades de relevo como os rios anteriormente analisados. Isso decorre do fato do mesmo não estar em contato com a Serra dos Lopes, isto é, não está diretamente envolvido na dinâmica transcorrente da alta bacia do Ribeirão dos Rodrigues, além de não possuir contatos entre litologias mais resistentes relacionadas ao Pré-Cambriano.

O Córrego da llha, localizado na margem esquerda da média/baixa bacia do Ribeirão dos Rodrigues, é influenciado por um extenso lineamento vinculado à Zona de Cisalhamento de Moreira. Este curso fluvial tem suas nascentes inseridas na vertente oposta do interflúvio que divide o Córrego da llha do Córrego do Sítio Velho, o qual apresentaram indícios de uma retomada erosiva recente evidenciada a partir do desenvolvimento de anfiteatros bem desenvolvidos.

Na análise do perfil longitudinal do Córrego do Sítio Velho (Figura 12), verifica-se nas cotas entre 700 e 680 metros anomalia negativa coincidente com os trechos retilíneos e as inflexões mencionadas.

Do mesmo modo, no setor entre as cotas altimétricas de 660 a 640 metros o perfil longitudinal mostrou uma anomalia positiva em relação à linha de tendência, indicando que possivelmente esta área do relevo está perpassando por soerguimento ou que o ajuste tectônico já ocorreu, no entanto, este setor do rio ainda não se encontra em equilíbrio (PHILLIPS, 2005). 


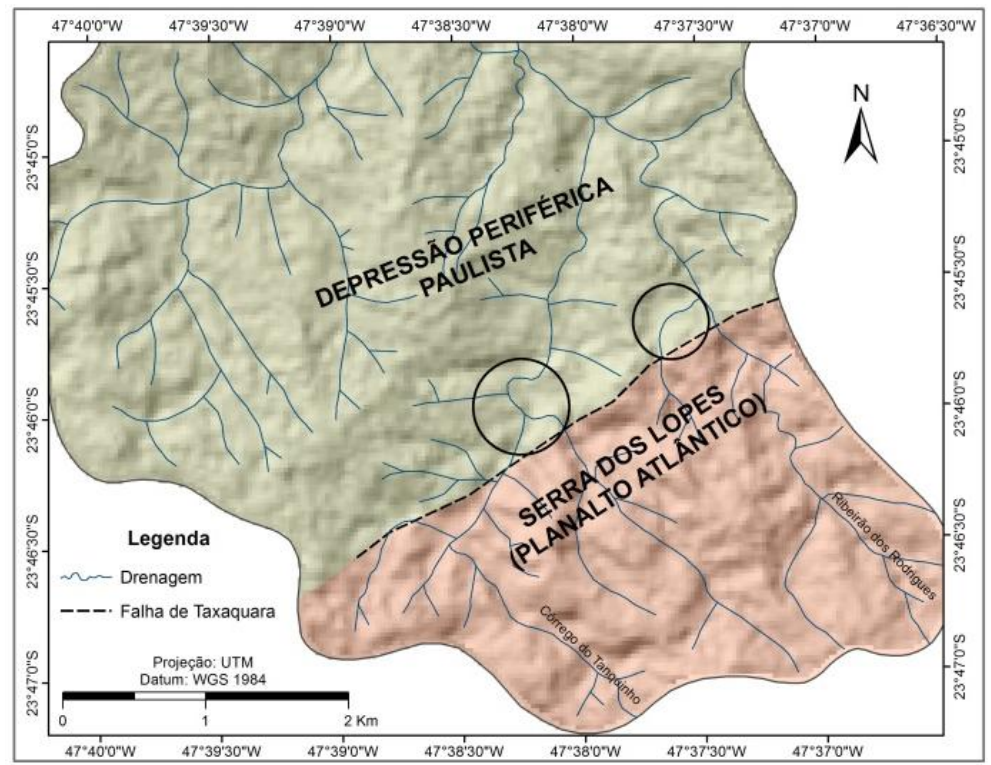

Figura 11: Localização dos desvios da drenagem na alta bacia (círculos no mapa) que caracterizam os processos de shutter ridges. A linha tracejada corresponde ao falhamento de Taxaquara.

Fonte: Adaptado de Souza (2013).

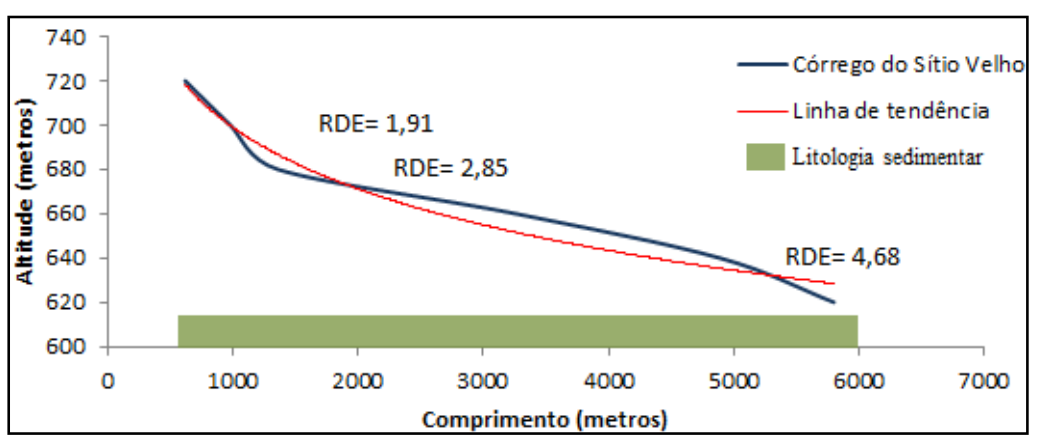

Figura 12: Perfil Longitudinal do Córrego do Sítio Velho.

Fonte: Souza e Arruda (2014).

Assim sendo, o setor de anomalia positiva refere-se a um possível alçamento deste trecho da bacia, que pode ter causado a migração de parte da drenagem para leste, inclusive no Ribeirão dos Rodrigues, como apontado no índice de assimetria da bacia de COX (1994). Além disso, tal anomalia positiva também está vinculada à entrada do curso d'agua em vale encaixado à estrutura geológica, onde no Figura 6 é indicado um lineamento de orientação aproximada E-W.

De modo geral as anomalias identificadas no Ribeirão dos Rodrigues, Córrego do Tanquinho e Córrego do Sítio Velho, podem estar associadas a controles estruturais e litológicos refletidos nos rearranjos dos perfis longitudinais.

As evidências de reorganizações da rede de drenagem e das formas do relevo, bem como a possibilidade de subsidência e ajustes de blocos responsáveis pelos desajustes dos rios 
podem estar vinculadas à reativação, durante o Mesozóico, de falhas pré-cambrianas cuja gênese está relacionada aos ciclos tectônicos mais antigos. A ressurgência da atividade tectônica durante o Cenozóico pode estar vinculada ao soerguimento proporcionado pela denudação e, consequentemente, exumação, das litologias e estruturas pretéritas. A atuação do clima sobre denudação da Serra dos Lopes e sua influência na exumação dessas estruturas também é importante questão a ser discutida, principalmente na alteração de níveis de base locais por sucessivas retomadas erosivas.

\section{CONCLUSÕES}

A partir das análises efetuadas, constatou-se que o relevo da bacia do Ribeirão dos Rodrigues, bem como o arranjo de sua drenagem, é resultado de eventos erosivos e deposicionais truncados por eventos tectônicos pretéritos e que possivelmente foram reativados no Quaternário tardio.

As anomalias de drenagem identificadas na bacia se relacionam diretamente com os controles estruturais evidentes nos principais alinhamentos e que estão vinculados à dinâmica transcorrente das Zonas de Cisalhamento de Taxaquara e de Moreira; além disso, as características litológicas da área também são importantes nos controles, em razão dos níveis de base intermediários identificados pelas rupturas topográficas presentes nos perfis longitudinais.

A Serra dos Lopes, superfície topográfica acima dos 700 metros é a principal responsável pelo fornecimento de sedimentos para as áreas adjacentes. Deste modo, o afloramento in situ de rochas cristalinas indica a ação dos processos erosivos responsáveis pela denudação e, consequentemente pelo recuo da escarpa para SSE, dando origem a feições que indicam a ação conjunta dos processos tectônicos e erosivos, com aparecimentos de facetas triangulares. Embora estas não sejam tão evidentes em campo, em função das coberturas superficiais associadas ao ambiente tropical úmido, forneceram importantes indicativos da reorganização do relevo durante o Quaternário.

A atual organização da rede de drenagem, bem como a presença de anomalias são fortes indicativos da influência da tectônica cenozóica nessa região. De qualquer modo, estudos complementares estão sendo realizados a partir da análise dos depósitos sedimentares na 
área, com o objetivo de correlacionar a interação entre tectônica e clima na configuração das formas de relevo na região.

\section{AGRADECIMENTOS}

À Fapesp pela concessão de bolsa referente ao período de 2012 à 2013; e ao Grupo de Estudos do Quaternário da Universidade Federal de São Carlos, campus Sorocaba (UFSCarSorocaba).

\section{BIBLIOGRAFIA}

AB'SABER, A. N. Regiões de circundesnudação pós-cretáceas no Planalto brasileiro. Boletim Paulista de Geografia, São Paulo, 1:1-21, 1949.

AB'SABER, A. N. O problema das conexões antigas e da separação da drenagem do Paraíba e do Tietê. Boletim Paulista de Geografia. 26:38-49, 1956.

$A B^{\prime} S A B E R, A$. N. A Depressão Periférica: um setor de áreas de circundesnudação póscretácica na Bacia do Paraná. Geomorfologia. São Paulo, 15:1-26, 1969.

ALMEIDA, F. F. M. Fundamentos geológicos do relevo paulista. Boletim do Instituto Geográfico e Geológico, vol.1: 167-273, 1964.

ARRUDA, E. M. Contribuição da dinâmica morfoestrutural e morfoescultural na estruturação da bacia do Ribeirão Entupido, Complexo Alcalino do Passa Quatro-SP. Universidade Estadual Paulista, Instituto de Geociências e Ciências Exatas. Rio Claro/SP: 2008. 148f. (Tese de Doutorado).

BIGARELLA, J.J.; MOUSINHO, M.R.; SILVA, J.X. Pediplanos, pedimentos e seus depósitos correlativos no Brasil. Boletim Paranaense de Geografia, Curitiba, 16/17: 117-151, 1965.

BISHOP, P. Drainage rearrangement by river capture, beheading and diversion. Progress in Physical Geography, 19(4): 449-473, 1995.

BISHOP, P. Long-term landscape evolution: linking tectonics and surface processes. Earth Surf. Process. Landforms, 32, 329-365, 2007.

BISHOP, P; YOUNG, R. W; MCDOUGALL, I. Stream profile change and longterm landscape evolution: early Miocene and modern rivers of the east Australian highland crest, central New South Wales, Australia. Journal of Geology, vol. 93, p. 455-474, 1985.

BOER, D. $\mathrm{H}$; Hierarchies and spatial scale in process geomorphology: a review. Geomorphology, 4, 303-318, 1992.

COX, R.T. Analysis of drainage basin symmetry as a rapid technique to identify areas of possible Quaternary tilt-block tectonics: an example from the Mississippi Embayment. Geol. Soc. Am. Bull., v. 106, p. 571-581, 1994.

CHRISTOFOLETTI, A. Considerações sobre o nível de base, rupturas de declive, capturas fluviais e morfogênese do perfil longitudinal. Geografia 8(4): 81-102, 1977. 
ETCHEBEHERE, M.L.C. Terraços Neoquaternários no vale do Rio do Peixe, Planalto Ocidental Paulista: Implicações estratigráficas e tectônicas. (Tese de Doutoramento) IGCE-UNESP, Vol.I, 264 p. e Vol.II, mapas. Rio Claro-SP, 2000.

ETCHEBEHERE, M. L; SAAD, A. R; FULFARO, V. J; PERINOTTO, J. A. J. Aplicação do Índice "Relação Declividade-Extensão - RDE" na Bacia do Rio do Peixe (SP) para deteç̧ão de deformações Neotectônicas. Revista do Instituto de Geociências - USP, v. 4, N. 2, p. 43-56, 2004

GONTIJO, A. H. F. Morfotectônica do médio vale do rio Paraíba do Sul: região da Serra da Bocaina, Estados de São Paulo e Rio de Janeiro. Tese de Doutoramento, 259p, 1999.

GUEDES, I. C; SANTONI, G. C; ETCHEBEHERE, M. L. C; STEVAUX, J. C; MORALES, N; SAAD, A. R. Análise de perfis longitudinais de drenagens da bacia do rio Santo Anastácio (SP) para a detecção de possíveis deformações neotectônicas. Revista UnG - Geociências, v. 10, p. 77104, 2006.

HACK, J. T. Stream profile analysis and stream gradient index. Journal Research of U. S. Geological Survey, v. 1, 421-429, 1973.

HASUI, Y; PONÇANO W.L; Bistrichi C. A. et al. As grandes falhas do Leste Paulista. In: SBG, Simp. Geol. Reg., 1, Atas, 369-380, 1977.

HASUI, Y. A grande colisão pré-cambriana do Sudeste brasileiro e a estruturação regional. Geociências (São Paulo. Impresso), v. 20, p. 141-169, 2010.

HIRUMA, S.T. Neotectônica no Planalto de Campos do Jordão, SP. Dissertação de mestrado, Instituto de Geociências-USP, p. 102, 1999.

HOWARD, A. D. Drainage analysis in geologic interpretation: A summation. Am. Assoc. Petrol. Geol. Bull. V 51, p. 2246-59, 1967.

MASSOLI, M. Relação Entre o Embasamento Cristalino e os Sedimentos Basais do Subgrupo Itararé na Região de Sorocaba-Salto de Pirapora, SP. São Paulo. (Dissertação de Mestrado, IG/USP), 1991.

MENDES, L. D; FERNANDES, N. F; GONTIJO-PASCUTTI, A. H. F. Morfotectônica da bacia hidrográfica do Rio Bonito, Petrópolis-RJ. Revista Brasileira de Geomorfologia, v.8, n.1, p. 6377. 2007.

MONTEIRO, C. A. de F. A Dinâmica Climática e as Chuvas no Estado de São Paulo - estudo geográfico sob a forma de atlas. São Paulo: Universidade de São Paulo/ Instituto de Geografia, 1973. 129 p.

MORAIS, M. D; ARRUDA, E. M. Impactos Ambientais Causados pela Urbanização na Bacia Hidrográfica do Ribeirão Cubatão, Município de Votorantim SP. In: 9o Simpósio Nacional de Geomorfologia - SINAGEO, 2012, Rio de Janeiro. Anais do 9o Simpósio Nacional de Geomorfologia SINAGEO. Rio de Janeiro, v. 1. p. 1-3, 2012.

OLIVEIRA, D. QUEIROZ NETO, J. P. Estudo da evolução do relevo na Serra do Mar no Estado de São Paulo a partir de um caso de captura fluvial. In: Geousp, São Paulo, 22, p. 73-88. 2007.

PHILLIPS, J. D. Weathering instability and landscape evolution. Geomorophology 67, 255$272,2005$.

PONÇANO, W.L; ALMEIDA, F.F.M. Superfícies erosivas nos planaltos cristalinos do Leste paulista e adjacências: uma revisão. Cadernos IG/Unicamp, v.3, n.1, 1993. 
RICCOMINI, C. O Rift Continental do Sudeste do Brasil. São Paulo, (Tese de Doutoramento apresentada ao Instituto de Geociências da Universidade de São Paulo), 256p., 1989.

RICCOMINI, C.; GROHMANN, C.H.; SANT'ANNA, L.G.; HIRUMA, S.T. A captura das cabeceiras do Rio Tietê pelo Rio Paraíba do Sul. In: May C. Modenesi-Gauttieri, Andrea Bartorelli, Virginio Mantesso-Neto, Celso D.R. Carneiro, Matias B.A. Lima (Ed.) A Obra de Aziz Nacib Ab'Saber, São Paulo, Beca-Ball, 1a Edição, p. 157-169. 2010.

SALVADOR, E.D; RICCOMINI C. Neotectônica da Região do Alto Estrutural de Queluz (SP-RJ, Brasil). R. bras. Geoc. 25 (3): 151-164.1995.

SANTOS NETO, O. M; ARRUDA, E. M. Influência da Rede de Drenagem na Morfodinâmica da Bacia do Ribeirão Jurupará, Serra de São Francisco SP. In: 9o Simpósio Nacional de Geomorfologia - SINAGEO, 2012, Rio de Janeiro. Anais do 9o Simpósio Nacional de Geomorfologia SINAGEO. Rio de Janeiro, v. 1. p. 1-3, 2012.

SÃO PAULO. Secretaria do Meio Ambiente. Mapeamento geológico da Folha de Salto de Pirapora-SP, 1:50.000. Relatório Técnico. Instituto Geológico, SP, 2009.

SOUZA, E. P; ARRUDA, E. M. Análise Morfoestrutural na Bacia do Rio Ipanema, Região de Sorocaba SP. In: 9o Simpósio Nacional de Geomorfologia SINAGEO, 2012, Rio de Janeiro. Anais do 9o Simpósio Nacional de Geomorfologia SINAGEO. Rio de Janeiro, v. 1. p. 1-3, 2012.

STRAHLER, A. N. Quantitative analysis of watershed geomorphology. Geophysical Union Trans., v.38, p.912-920, 1957.

VALADÃO, R.C. Evolução de longo-termo do relevo do Brasil Oriental (desnudação, superfícies de aplainamento e soerguimentos crustais). UFBA, Salvador, Tese de Doutorado, 243 p, 1998.

VESELY, F. F.; ASSINE, M. L. Deglaciation sequences in the Permo-Carboniferous Itararé Group, Paraná Basin, southern Brazil. Journal of South American Earth Sciences, v. 22, p. 156-168, 2006.

VILLELA, F. N. J.; SANCHES ROSS, J. L.; MANFREDINI, S. Relief-Rock-Soil relationship in the transition of Atlantic Plateau to Peripheral Depression, Sao Paulo, Brazil. Journal of Maps, v. 1, p. 1-10, 2013.

VITTE, A. C. Relações entre a estratigrafia das rampas de colúvio e a evolução das vertentes na bacia do Ribeirão Juncal, município de Salto de Pirapora (SP). Anais do X Encontro de Geógrafos da América Latina. Universidade de São Paulo, 2005.

SOUZA, A. O; ARRUDA, E. M. Análise da Rede de Drenagem na Bacia do Ribeirão dos Rodrigues: Anomalias, Índice RDE e Perfil Longitudinal. Revista Brasileira de Geografia Física. , v.7, p.442 - 457, 2014.

SOUZA, A. O. Estudo das anomalias de drenagem da bacia hidrográfica do Ribeirão dos Rodrigues, Serra dos Lopes-SP. 2013. 109 f. Trabalho de Conclusão do Curso de Licenciatura em Geografia. Universidade Federal de São Carlos, Sorocaba-SP.

$\begin{array}{cc}\text { Artigo submetido em } & \text { 25/08/2014 } \\ \text { Artigo aceito em } & \text { 21/01/2015 }\end{array}$

